\section{MEDICAL DISEASES OF WAR}

By Sir Arthur Hurst, M.A., D.M., F.R.C.P. (with the Co-operation of others). 4th Edition. Pp. 5II. Edward Arnold \& Co. London. 1944. Price 21s. net.

In extending a warm welcome to the fourth edition of Hurst's well-known Medical Diseases of War, the reviewer is under the sad duty of recalling that the chief author and at least one of his contributors are no longer with us. But Hurst's robust thought and writing has a lasting stimulus, and T. A. Ross likewise remains a master to those who survive him.

Sixteen of the twenty-nine chapters, and perhaps two hundred pages, are directly or indirectly devoted to the psychological disorders of warfare. That this amount is not out of proportion will scarcely be denied by any who have had experience of medical casualties in the war so recently endea. But it must be confessed that the bias of the argument of this large portion of the book belongs to the first World War. Hysteria is allotted ten chapters to itself, as against one each for Anxiety Neurosis and Neurasthenia. Schizoid reaction-types, psychopathic personalities, and mental deficiency are barely mentioned. Hurst's experience of those who suffer from hysteria was of the heroic kind of a generation of doctors that is gone or going. The grossest palsies, blindness, deafness, stupors, were to him the every-day manifestations. The present symptoms (the headaches, giddiness, faints, and dyspepsias either did not exist for him-or were ascribed to other mechanisms. Only in the matter of hysterical fugues are we on approximately common ground. But though the reader of to-day may have difficulty in identifying his own war-experiences with the story told him in these pages, he will find that the writing never loses its fire. The interest of comparing what he has seen with what his fathers saw, and of pondering over the way disease may change its character in only a few years, will spare him from the smallest fear of boredom or uneasiness.

The rest of the book is excellent. Here are discussed the organic diseases that come to the physician in war, and it is unjust to single out any section for special commendation. There is a fine blending of old and new experiences. For example, it is well that we who have come to regard bacillary dysentery as a relatively trivial disorder shall be brought face to face with its ravages on our man-power in Gallipoli, Salonica, and the Middle East only a quarter of a century ago.

If the reviewer allows himself to state his special liking for the chapter on Louse-borne Typhus Fever by Dr. M. D. Mackenzie, he does so because of the particular advances in this field during the Second World War and because he feels that, in the years immediately before us, the chaos of Europe will effectively prevent us from ignoring the knowledge gained.

And this really gives the clue to the value of the book. Even in Medicine, we cannot afford to forget the past, and, with the new edition of Hurst, we can buy an insurance-policy against the failure of our memories.

\section{STUDIES OF BURNS AND SCALDS BY THE MEDICAL RESEARCH COUNCIL}

Published by H.M. Stationery Office.

This is a most excellent publication on the subject of burns, and one which should be in the hands of all those having charge of accident wards. A unique feature is a clinical chapter in which there are depicted diagrams showing the degree and extent of the patient's burn, with underneath a copy of the patient's pulse chart and haemoglobin concentration results, showing how the degree of shock was manifested and combated.
THE MEDICAL ANNUAL 1945

Edited by Sir Henry Tidy and A. RFndle Short. John Wright and Sons, Ltd., London. Simpkin Marshall (194I), Ltd. 410 pp., 6r illustrations and 47 plates. 25s. net. Bristol.

Once again the Medical Annual is with us-in its $63 \mathrm{rd}$ consecutive year, and the publishers and 44 contributors deserve the congratulations and gratitude of the profession for having done their work so well, as it were to spite the evil days in which we have existed rather than lived. Much more than a year-book-for it looks on change as not always progress and on fashion as often fad-as a critical review, alphabetically arranged, of the year's advances in medicine, surgery, and the specialities, it is indispensable to practitioners, research workers, teachers, and authors. To some it is a short cut, to others an introduction, to the medical literature. Throughout it is very readable, its atmosphere being refreshingly leisurely. There is no unseemly haste to keep up with time.

Sir Henry Tidy writes on dyspepsia and peptic ulcer in the services, and on the medical aspect of gastric and duodenal ulcer, while his co-editor deals with the surgical aspect. Some of the contributions which have caught the reviewer's eye include a nine page review of penicillin, gold in rheumatoid arthritis, thiouracil in thyrotoxicosis, mass radiography of the chest, prevention of sea sickness, and primary atypical pneumonia. Sir Walter LangdonBrown and S. L. Simpson contribute a masterly summary of stilboestol and cancer. A review of vital statistics by Dr. Percy Stocks is included for the first time.

The usual lists are appended of the Books of the Year and of recent pharmaceutical products with the manufacturer's name and address and brief descriptions supplied (it is emphasised) by the makers. The General Index has been most carefully compiled. In the reviewer's copyô Plates XXVI to XXIX have been inserted upside-down "Ferguson," on p. 300, 1.5 from the top, should reaf "Fergurson."

\section{FORWARD SURGERY IN MODERN WAR}

By W. H. OGilvie, M.A.M.D., M.C.H., F.R.C.S., Hon. F.A.C.S., Hon. F.R.C.S.(C.) Published by Butterworth \& Co. Ltd., London, I944. Price Io/6.

This is an excellent short treatise as to the surgical practice suggested for front-line casualty clearing stations. As to the surgical views and treatment, there can be little criticism, but it is a pity that the author has not devoted more space to describing the organisation of casualty clearing stations, which is the information which a new entrant to the services would most welcome.

\section{FRACTURES AND ORTHOPAEDIC SURGERY} FOR NURSES AND MASSEUSES

By Arthur Naylor. Published by E. \& S. Livingstone

\section{Ltd. Edinburgh. 1945. I6/-}

Mr. Naylor has written a most excellent little book on orthopaedic surgery, which will be read by medical men with great interest and advantage, but as a teacher of nurses, I would myself say that it conveys very little information to them on the treatment of these cases. Certainly it does not help any nurse to put up or supervise any of the weight and pulley or other extension apparatus which she will use in the treatment of fractures.

There would appear to be very little to help the average $N$ physio-therapist. No detailed information is found as to $N$ the great value that electric tests would give to help a surgeon who is not sure as to whether to explore a nerve injury, whilst there is very little information for the 0 masseuse as to the pathology of traumatic oedema, and $\frac{}{\Phi}$ the subsequent bugbear of preventing adhesions forming, 舫 which is one of the main objects of any masseuse working in a fracture department. 